\title{
Determination of the Business Ecosystem Key Characteristics in the Economic and Legal Space
}

\author{
I. Tkachenko, L. Ramenskaya*
}

Ural State University of Economics, Ekaterinburg, Russia

${ }^{*}$ Corresponding author.Email: ramen_lu@mail.ru

\begin{abstract}
There are two key characteristics of ecosystems were identified and described in the article, based on bibliographic analysis: boundaries and stakeholders. Based on the analysis of definitions, the main approaches to defining the boundaries of ecosystems determined: relationships with the leader through relations of control, exposure to institutional impact, localization and belonging to a value creation network. When comparing them, it was concluded that the most universal and promising ways of defining boundaries are exposure to institutional impact and belonging to a value creation network. We highlighted and described the key roles of ecosystem stakeholders: leader, priority stakeholder, complementator, including the participants, relations with which characterized by the term "coopetition". The main provisions illustrated by examples of Russian ecosystems formed based on digital platforms.
\end{abstract}

Keywords: ecosystem; digital platform, economic sustainability, stakeholders, boundaries.

\section{INTRODUCTION}

In the context of innovative and technological development and transformation of business architecture, there is an active transition from independent business structures to integrated associations, network structures and ecosystems. This transformation of the modern economy largely influenced by the development of digital technologies. Ecosystems, on the one hand, depend on the level of development of digitalization, on the other hand, they themselves give impetus to the further development of digital infrastructure, including information, organizational, marketing, educational, network and other institutions that help a new innovative idea to get to its practical implementation and find its own consumer. The higher the degree of development of the digital infrastructure, the higher the degree of influence of the data used on the management practice, the higher the level of consistency between the ecosystem participants, the higher the inter-firm interaction, the stronger the cross-functional communications of individual entities interacting in ecosystems, which ensures sustainable development of the ecosystem as a whole. E.V. Popov and Simonova V.L. (2021) rightly noted that an ecosystem is an evolutionary stage in the development of inter-organizational networks and is a system of interacting, exchanging resources of subjects that transform some of their types into others [1]. It is digitalization that has contributed to the creation of ecosystems, the high efficiency of which and the achievement of the ecosystem effect can only ensure a high level of cooperation and harmonization of the interests of the participants. Interaction at this level of relationships increases the value of the ecosystem for individual entities, attracts more and more new participants to cooperation, and contributes to the further development of the ecosystem along the path of its innovation.

Ecosystems are composed of interacting organizations that are digitally connected and operate in a modular fashion and not managed hierarchically. In the institutional dichotomy "market - hierarchy" ecosystems occupy an intermediate position. In engineered ecosystems, organizations come together to create networks.

At present, ecosystems have become one of the key concepts for describing the realities of modern business that are in demand by researchers and practitioners. Modern ecosystems have a significant impact on the state, society, and transform markets.

At the same time, growth and unregulated growth of ecosystem giants can threaten economic sustainability at the macro and micro levels, as it intensifies competition with the world's leading technological platforms that form their own ecosystems, and also subordinates market participants to the "rules of the game" formed by leaders. 
There are several strong national ecosystems in Russia, developed by large digital platforms. The leading role in the development of national ecosystems belongs to the financial sector (Sber, Tinkoff, VTB) and technology giants (Yandex, Mail.ru Group, MTS).

In order to become a full-fledged object of analysis, an ecosystem must be uniquely identifiable. The identification of ecosystems in economic and legal contexts is especially significant.

The importance of ecosystem identification in a legal context is due to the need for regulatory regulation of aspects related to the activities of ecosystems that threaten economic sustainability. The main hazards associated with the activities of ecosystems in the legal space are the following: anticompetitive practices arising from a monopoly market position; exclusive access to "big data", which, on the one hand, is the intellectual property of the party that extracted it, on the other, like any intellectual property, should have a limited period of protection of rights; corporate control of platforms, including corporate censorship practices, supervision of user and employee actions.

The importance of identification in the economic context is due to the fact that ecosystems are becoming the main object of economic analysis at the meso-level, replacing industry analysis.

\section{MATERIALS AND METHODS}

Bibliographic analysis is the main method of this research. The research information base was composed of articles from the Web of Science Core Collection information base. In total, 159 articles were analysed for the period from 2000-2021, including 27 definitions.

\section{RESULTS AND DISCUSSION}

Ecosystem characteristics differ significantly in the studies of various authors. So, R. Adner identifies four key characteristics of ecosystems [2, p. 43]: types of activities, role structure of actors-participants, positions of participants, connections that determine the interaction between them. G.B. Kleiner proposes a methodological basis for the study of an ecosystem, which includes four components - an organizational component (organizations and independent individuals), an infrastructure environment (institutions, regulations), communication and logistics (business processes) and innovative components (adaptation of the ecosystem to the external environment) [3].

The purpose of this article is to somewhat expand the list of ecosystem characteristics to include a description of the boundaries and key stakeholders.

To identify the belonging of the considered subject to the ecosystem, its boundaries should be identified. The border is the basic identification characteristic. From the point of view of the systems approach, the specification of the boundaries of the ecosystem encounters a number of difficulties. First, the difficulties caused by the fact that the ecosystem is a complex open system that exchanges resources and information with the external environment, in which the relationship between the components is more important than themselves. Second, in accordance with the original definition of J. Moore [4], the components of the business ecosystem are subject to coevolution, therefore, the composition of participants and their roles in the ecosystem are constantly transforming.

In accordance with the provisions of the theory of complex adaptive systems (CAS) [5], the boundary of an ecosystem is not a perimeter, but an important functional component that allows you to get a more complete picture of its interaction with the environment; the boundaries of the ecosystem are dynamic, therefore, the task of their clear fixation should not be set; the boundaries of individual ecosystems can overlap.

Based on the analysis of definitions, four main approaches to describing the boundaries of an ecosystem were identified (Table):

1. Relationship with the leader through a relationship of control; A fairly common point of view is that an ecosystem is a special case of a focal interorganizational network, according to which its boundaries are determined on the basis of identifying the relationship with the leader. The leader forms the architecture of the ecosystem, creating its components based on an understanding of the logic of its development, including using the tools of mergers and acquisitions.

Ecosystems of this kind are platforms that seek to monopolize activities in all directions. For example, the largest emerging ecosystems of digital platforms in Russia (Sber, Yandex, Mail.ru Group) created by the leader based on an assessment of the capabilities of their own digital platforms and business prospects.

2. Exposure to institutional impact; Compliance of ecosystem participants with the rules and principles, interaction interfaces, formed by the leader. In our opinion, this aspect should highlighted separately, since in this case; ecosystem participants can come independently, accepting the "rules of the game" of the ecosystem.

The main example is open digital platforms, which can entered by any subject, following the rules: opening a store on the marketplace; adding a new artist to the service of streaming music playback platforms; connecting a new driver to the taxi service, etc. 
Table 1. Essential characteristics of approaches to defining business ecosystems

\begin{tabular}{|c|c|c|c|}
\hline $\begin{array}{l}\text { An approach to defining } \\
\text { an ecosystem }\end{array}$ & $\begin{array}{l}\text { Relationship with Exposure to institutional } \\
\text { the leader through aimpact } \\
\text { relationship of } \\
\text { control }\end{array}$ & Localization & $\begin{array}{l}\text { Belonging to a value } \\
\text { creation network }\end{array}$ \\
\hline The boundaries & $\begin{array}{l}\text { The ecosystem is The ecosystem is limited } \\
\text { limited by the by the rules and } \\
\text { architecture formed regulations of the } \\
\text { by the leader }\end{array}$ & $\begin{array}{l}\text { Territorial, sectoral, } \\
\text { combination thereof }\end{array}$ & $\begin{array}{l}\text { The ecosystem is limited by } \\
\text { the value proposition }\end{array}$ \\
\hline Leader's Role & \begin{tabular}{|l|l|} 
Orchestration of Formation of common \\
participants, \\
formation and argetinteraction \\
architecture
\end{tabular} & $\begin{array}{l}\text { May not be explicitly } \\
\text { highlighted, may include the } \\
\text { creation of general rules of rules } \\
\text { and conditions for interaction }\end{array}$ & $\begin{array}{l}\text { The owner of the main asset } \\
\text { eproviding the base for value } \\
\text { screation }\end{array}$ \\
\hline $\begin{array}{l}\text { Limitations of } \\
\text { approach }\end{array}$ & \begin{tabular}{|l|l|} 
Does not allow & Difficulty of detection in \\
describing & case of latent interaction \\
ecosystems without rules \\
a leader or with \\
variable leadership
\end{tabular} & $\begin{array}{l}\text { Doesn't allow describing virtual } \\
\text { systems }\end{array}$ & $\begin{array}{l}\text { Difficulty in identification, } \\
\text { since the border is subject to } \\
\text { constant transformation }\end{array}$ \\
\hline Application area & \begin{tabular}{|l|l|} 
Digital platforms & $\begin{array}{l}\text { Applicable to any type of } \\
\text { ecosystem }\end{array}$ \\
\end{tabular} & $\begin{array}{l}\text { Territorial, industry, university } \\
\text { ecosystems }\end{array}$ & $\begin{array}{l}\text { Applicable to any type of } \\
\text { ecosystem }\end{array}$ \\
\hline
\end{tabular}

3. Localization; This group of definitions is based on the localization of ecosystems [6] as one of the most important characteristics. Most often, an ecosystem is distinguished by belonging to the territory of presence (for example, Silicon Valley), industry or field of activity, or their combination (Moscow digital ecosystem).

4. Belonging to a value creation network; The founder of the fourth approach to the definition of ecosystems is R. Adner, who proposes to consider an ecosystem as "the alignment structure of the multilateral set of partners that need to interact in order for a focal value proposition to materialize" [2, p. 40]. In this case, the key point is co-creation of the ecosystem participants. In this case, the boundaries of the ecosystem can be determined through the belonging of individual entities to the value creation network.

The idea of value networks develops the concept of "value chain" by M. Porter [7]. Followers have developed this idea for a network of organizations, in which each stage of customer value creation can be provided by multiple organizations, which makes it possible to talk about a value chain network.

In ecosystems, there can be two models in the behavior of participants: some participants actively create value, being the driver of the development of new scientific knowledge, breakthrough technologies focused on increasing the value of social and economic benefits. These are value creators. Other members of the ecosystem can join the existing platform and find separate points of value for themselves and their customers. They are passive participants in ecosystems who are consumers of the created technologies and values. But even for a small company with far fewer resources, being part of the ecosystem does not mean simply being a recipient of value and profit. Small companies - participants in ecosystems - also need to participate in co-creating value and see how much of the benefit they receive, appreciate it, and really be part of the ecosystem.

An individual actor gains additional value from participation in the ecosystem. This added value can be a consequence of access to complementary resources of competencies, information, customer base, opportunities to co-create innovation with other participants, etc.

Digitalization as one of the prerequisites for the development of the ecosystem mode of interaction as a whole leads to a decrease in transaction costs by reducing the cost of communications, eliminating intermediaries from value chains.

Reducing transaction costs of ecosystem participants is due to the use of a single digital space (digital platform, marketplace); access to proactive analytics based on big data processing by the platform leader; using the concept of user experience, etc.

In addition, it is possible to reduce costs due to more efficient use of resources and competencies of the company's employees.

Based on the comparison of approaches, it can be concluded that despite the fact that today the boundaries of real ecosystems are most often described either through localization or by identifying a direct relationship with the leader, the most universal and promising from the point of view of the theory of complexity are approaches to defining boundaries through exposure to institutional influences and belonging to a value creation network.

The second key characteristic of an ecosystem is a list of stakeholders (stakeholders).

In an ecosystem, values created for its individual subjects and actors, and common values formed while taking into account the interests of a wide range of stakeholders and their contribution to the increment of 
value. After all, the total value according to Porter and Kramer (2011) is a management socially oriented practice of increasing the financial efficiency of companies, an organic part of its business processes and strategy; combining profit making with meeting social needs [8].

The key roles of ecosystem actors are as follows:

The leader of the ecosystem, the role of the leader transformed depending on the approach to describing the boundaries (table). From the standpoint of the value approach, the leader is the main actor who actively creates value, playing the role of a driver for the development of new scientific knowledge, breakthrough technologies focused on increasing the value of social and economic benefits.

Priority Stakeholder: The party that benefits most from participating in the ecosystem and therefore pays for everyone. Other groups are providers of data and services that attract the priority group, therefore they do not pay (or pay insignificantly) for access to the ecosystem [9].

In particular, for the Russian market leaders of digital platforms ecosystems mentioned earlier, in the B2C segment, obviously, the priority stakeholder is an individual - a user of the basic ecosystem product, who is maximally involved in using other services. For Sber, this is a user of banking services, for Yandex, a user of a search service, and for Mail.ru Group, a user of a social network VK.

It is obvious that the development of these ecosystems is in the direction of anticipating and covering the needs of this priority group, which is expressed in the fact that all the digital platforms under consideration implement services in the same list of areas of activity: media and entertainment, finance, shopping, food, work, education, health, etc.

Complementators are providers of complementary goods, sources of added value.

Ecosystems are subject to network effects, which are based Metcalfe's law: the value of the network for the user is proportional to the number of connection nodes [10]. At the same time, it is necessary to achieve a critical mass of users, after which the value will grow.

For example, the more drivers connected to the Yandex. Taxi service, the higher the quality of the service (delivery speed, service level, and price). Hence, the higher the value to the end user.

The experience of the largest digital platforms shows that strategies for attracting complementators to the ecosystem can differ. So, «Sber» characterized by the centralized formation of ecosystem architecture, in which complementators are selected to solve specific problems in the business architecture. At the same time, the company spends significant resources both on the purchase of ready-made businesses that provide the required services, and on the creation of their own. «Yandex» mainly creates its own services, paying special attention to the possibility of integration with existing ones. «Tinkoff», on the other hand, is actively developing an affiliate program, which can be accessed from a single application (superapp).

At the same time, among the complementors, two groups of stakeholders that are completely different from others can distinguished.

Independent contractors. A number of platforms use the labor of "independent contractors" instead of workers. In Russia, these employees registered as individual entrepreneurs or as employees of platform partner firms. Delivery couriers and taxi drivers are just a few of the "independent contractors". The benefits of this employment model for platforms are associated with savings in taxes and fees. On the other hand, "independent contractors" do not fall under the labor law, which entails the absence of vacations, paid sick leave, severance pay upon dismissal, and record of seniority. An acute issue affecting both sides of the interaction is also the control of working conditions and the prevention of overtime.

Another special complementators are another platforms, relations with which can be described using the term "coopetition" - the partnership of competitors.

When interacting in an ecosystem, the very concept of competition changes qualitatively. By creating value, the ecosystem actor does this not in isolation, not only for himself, but also for other participants in the ecosystem. In this regard, interesting thoughts about the formation of the so-called ecosystem thinking were expressed by MBA professor Shahzad Ansari in his lecture on digital transformation and breakthrough innovations, read on the RBK-RPO channel (2021): "We need to think in crossindustry categories, ecosystem categories ... The key aspect the ecosystem worldview is that you believe in making the pie bigger, not getting the biggest piece of that pie. Even if your slice is small, the pie is so large that you still benefit more from having even a small slice of this larger pie. Co-creation should be part of your thinking. You shouldn't think like a loner working in isolation "[11]. Indeed, the key word in ecosystems is collaboration. Collaboration applies to competitors as well. Such collaboration is necessary to have the same opportunities that your competitor already has in order to create more value together. You need to have a wide enough outlook in order to cooperate with competitors, and not see them only as enemies. They are friends and rivals in the ecosystem.

As the researchers note, these relations, due to their paradoxicality, require constant work on the harmonization of such relations. The forces of 
cooperation must outweigh the forces of competition, otherwise the effect of cooperation will be negative [12].

As an example of successful cooperation, one can cite cooperation «Sber» with Mail.ru Group, whose services compete in some areas (for example, real estate, health) and create joint services in others (joint services in the food segment - Sbermarket, Delivery Club). At the same time, the cooperation between «Sberbank» and "Yandex» ended with the separation of assets, due to the fact that both platforms decided to develop many competing areas in their ecosystem. As a result, each of them lost a successful service in one of the key areas and was forced to develop it from scratch.

\section{CONCLUSION}

Ecosystems are penetrating deeper and deeper, transforming markets and impacting society as a whole.

The need to ensure the economic sustainability of individual industries and the country as a whole leads to the need to develop a new type of regulatory policy. Understanding how ecosystem participants can defined and their boundaries described can reduce the complexity of identifying and analyzing ecosystems.

\section{ACKNOWLEDGMENTS}

The article was prepared with the financial support of the Russian Foundation for Basic Research and the Sverdlovsk Region within the framework of scientific project No. 20-410-660032 r_a

\section{REFERENCES}

[1] Ye.V. Popov, V.L. Simonova, Interfirm interactions, URAYT publishing house, p. 276 (2021).

[2] R. Adner, Ecosystem as structure: an actionable construct for strategy. In: Journal of Management, 43(1) (2017) pp. 39-58. DOI: https://doi.org/10.1177/0149206316678451.

[3] G.B. Kleyner, Socio-economic ecosystems in the light of the systems paradigm. In: Kleyner G.B., Shchepetova S.E. (eds.). Sb. tr. V Mezhdunar. nauch.-prakt. konf. - biennale (21-23 noyabrya 2018 g.) (Proc. of the 5th Int. sci.-pract. conf. biennale. November 21-23, 2018). Moscow: Prometey (2018).

[4] J. F. Moore, Predators and prey-A new ecology of competition. In: Harvard Business Review, 71(3) (1993) pp. 75-86.

[5] P. Cillers, Critical Complexity. Berlin/Boston: Walter de Gruyter GmbH \& Co KG, p. 312 (2016). https://doi.org/10.1142/S1363919601000312
[6] G.B. Kleyner, Ecosystem economy: Step into the future. In: Economic Revival of Russia, 1(59) (2019) pp. 40-45.

[7] M.E. Porter, Competitive Advantage. New York: The Free Press, 1 (1985) pp. 11-15.

[8] M.E. Porter, M.R. Kramer, Creating Shared Value: How to Reinvent Capitalism and Unleash a Wave of Innovation and Growth. In: Harvard Business Review, January/February, pp. 63-70 (2011).

[9] S.A. Yablonskiy, Multi-sided platforms and markets: basic approaches, concepts and practices. In: Russian Management Journal, 11(4) (2013) pp. 57-78.

[10] S.A. Djatlov, Theoretical approaches to assessing network effects. Modern Management Technology (2017). https://sovman.ru/en/article/7601.

[11] Sh. Ansari, Digital transformation: what is important for a manager to know: a lecture at RBCPRO by a professor of MBA programs at the Cambridge and Rotterdam Schools of Management, an expert in strategic management and innovation (2021). https://pro.rbc.ru/lecture/5f6d95fc9a7947575b8c2e 32.

[12] J.M. Crick, D. Crick, The Yin and Yang nature of coopetition activities: Non linear effects and the moderating role of competitive intensity for internationalised firms. Loughborough University. Journal contribution (2020). 